\title{
Estrogen's bone-protective effects may involve differential IL-1 receptor regulation in human osteoclast-like cells
}

\author{
Teresa Sunyer, ${ }^{1}$ Jennifer Lewis, ${ }^{1}$ Patricia Collin-Osdoby, ${ }^{1,2}$ and Philip Osdoby ${ }^{1,2}$ \\ ${ }^{1}$ Department of Biology, and \\ ${ }^{2}$ Division of Bone and Mineral Research, Washington University, St. Louis, Missouri 63130, USA
}

Address correspondence to: Philip Osdoby, Department of Biology, Box 1229, Washington University, St. Louis, Missouri 63130, USA. Phone: (314) 935-4044; Fax: (314) 935-5134; E-mail: osdoby@biodec.wustl.edu.

Portions of this work were presented in abstract form at the Nineteenth Annual Meeting of the American Society for Bone and Mineral Research in Cincinnati, Ohio, USA. September 10-14, 1997.

Received for publication July 23, 1998, and accepted in revised form April 16, 1999.

\begin{abstract}
Declining estrogen levels during the first postmenopausal decade lead to rapid bone loss and increased fracture risk that can be reversed by estrogen replacement therapy. The bone-protective effects of estrogen may involve suppression of inflammatory cytokines that promote osteoclastogenesis and bone resorption, such as IL-1, TNF- $\alpha$, and IL-6. We investigated whether estrogen modulates IL-1 actions on human osteoclasts (OCs) and other bone cell types. Isolated human OCs and primary bone marrow-derived OC-like cells expressed both the signaling (IL-1RI) and decoy (IL-1RII) IL-1 receptors, whereas only IL-1RI was detected in osteoblasts. IL-1RII/IL-1RI mRNA ratios and release of soluble IL-1RII (sIL-1RII) were lower in OC-like cells derived from women in the late postmenopausal period compared with younger women, but were unrelated to male donor age, suggesting that estrogen might play a role in regulating IL-1 receptor levels in vivo. Estrogen directly reduced in vitro OC-like cell IL-1RI mRNA levels while increasing IL-1RII mRNA levels and sIL-1RII release. These estrogenic events were associated with inhibited IL-1-mediated cytokine (IL-8) mRNA induction and cell survival, i.e., increased apoptosis. In contrast, estrogen did not alter IL-1R levels or IL-1 responsiveness in primary human osteoblasts or bone marrow stromal cells. We conclude that one novel mechanism by which estrogen exerts bone-protective effects may include a selective modulation of IL-1R isoform levels in OC or OC-like cells, thereby reducing their IL-1 responsiveness and cell survival. Conversely, this restraint on IL-1 actions may be lost as estrogen levels decline in aging women, contributing to an enhanced OC-mediated postmenopausal bone loss.
\end{abstract}

J. Clin. Invest. 103:1409-1418 (1999).

\section{Introduction}

The rate of bone loss in women is rapid and accelerates during the first decade after menopause, and estrogen replacement therapy is an effective means of slowing bone decay and thereby reducing fracture risk in postmenopausal women (1). Recent studies have revealed that estrogen also plays a key role in bone turnover in men $(2,3)$. The antiosteoporotic actions of estrogen are complex but ultimately result in a suppression of osteoclast-mediated (OC-mediated) bone resorption (4). Estrogen acts on other bone cell types to indirectly influence OC resorption; however, evidence for a direct action of estrogen on OCs has also been suggested by studies documenting that isolated avian and mammalian OCs and OC-like cells possess estrogen receptors and are estrogen responsive (5-9). In particular, estrogen has decreased key OC-resorptive enzymes, inhibited OC bone resorption $(6-8,10)$, and promoted OC apoptosis (11), processes that favor a positive bone balance. Despite these findings, uncertainty remains as to whether human OCs express functional estrogen receptors. For example, estrogen receptor mRNA was detected in highly purified OC-like cells isolated from human giant cell tumors of bone by some (7) but not other (12) investigators.
Apart from the controversy over potential direct actions of estrogen on OCs, the bone-protective effects of estrogen can be mediated by paracrine mechanisms involving nonosteoclastic cell modulation of OC formation and activity. Such indirect actions appear to be due to decreased levels or bioactivity of cytokines that promote OC development or activity, such as IL-6, IL-1, and TNF- $\alpha$ (13-15). Thus, estrogen depletion either after menopause in women or ovariectomy in female rats induces IL-1 production from peripheral blood monocytes and bone marrow cells (16-19) and IL-6 production from bone marrow stromal cells and osteoblasts (20). Estrogen treatment conversely suppresses such cytokine induction $(16,20,21)$, as does administration of IL-1 receptor antagonist (IL-1Ra), a natural competitor of IL-1 (22). Similarly, TNF binding protein, an inhibitor of TNF, or IL-6 neutralizing antibodies alleviate estrogen-deficient bone loss (23-25). These and other studies suggest that IL-6, IL-1, and TNF- $\alpha$ likely mediate the loss of bone caused by estrogen deficiency.

IL-1 is a key proinflammatory mediator implicated in the pathogenesis of various diseases associated with bone loss, such as osteoporosis $(26,27)$, tumor-associated osteolysis $(28,29)$, periodontal disease $(29,30)$, rheumatoid arthritis $(31,32)$, and orthopedic implant osteolysis (33). 
IL-1 is a potent in vivo and in vitro stimulator of bone resorption owing to its promotion of OC differentiation, OC-resorptive activity $(34,35)$, and OC cell survival $(36$, $37)$. It has been postulated that IL-1 acts indirectly on OCs through the release of soluble factor(s) from osteoblasts and other marrow cells (38). For example, high-affinity binding of IL-1 to IL-1 signaling receptors expressed on osteoblasts leads to a paracrine modulation of OC development and activity (34). However, some evidence also exists for a direct effect of IL-1 on OCs. IL-1 has been shown to raise intracellular $\mathrm{Ca}^{2+}$ levels in isolated individual rabbit OCs (39) and to activate NF- $\mathrm{KB}-$ like transcription factors in purified murine OC-like cells (40); IL-1 receptor mRNA has been detected in rodent OCs by in situ hybridization (41); and IL-1 treatment of purified human OC-like cells has stimulated the release of IL- 6 , TNF- $\alpha$, and IL- $8(42,43)$. The biologic effects of IL-1 on bone depend on complex interactions among many factors, including IL- $1 \alpha$, IL- $1 \beta$, IL-1Ra, IL- 1 receptors, and IL-1 receptor accessory protein. Two distinct IL1 receptors are known: the type I, or signaling, receptor (IL-1RI) that mediates cellular responses to IL-1 and binds equally well IL-1 agonist and antagonist; and the type II, or decoy, receptor (IL-1RII) that preferentially binds IL-1 agonist over antagonist but does not elicit intracellular signaling and which is often proteolytically cleaved at the plasma membrane to be released into the extracellular milieu as soluble IL-RII (sIL-1RII) (44). Therefore, possible direct effects of IL- 1 in regulating OC bone resorption might depend not only on the levels of IL-1 $\alpha$, IL-1 $\beta$, or IL-1Ra secreted by osteoblasts or other bone marrow or circulating cells, but also on the amount and type of IL-1 receptors expressed by the OC. Here we report for the first time to our knowledge that authentic bone-resorbing human OCs isolated from femoral heads (45), as well as primary cultures of closely related human bone marrow-derived OC-like cells, express mRNA for both the signaling and decoy IL-1Rs, as well as for estrogen receptor (ER). Moreover, we demonstrate that estrogen specifically regulates IL-1 receptor subtype expression in human OC-like cells in such a way as to diminish their biologic responsiveness to IL-1 and increase their

\section{Figure 1}

hOC and hOCL cells express mRNA for both the type I and type II IL-1 receptors. (a) Schematic representation of the human IL-1 receptor genes. Hatched bars represent the extracellular regions of the proteins; filled bars represent the transmembrane domains; and open bars represent the intracellular tails. Arrowheads indicate the location of primers used in RT-PCR. (b) RT-PCR of IL-1RI (I) and IL-1RII (II) from hOCs directly isolated from a femoral head of a 76-year-old woman undergoing hip replacement surgery, and from hOCL and hOBL cells generated from a single bone marrow mononuclear preparation derived from a 58 year-old woman. Amplicons were separated in 1.5\% agarose gels and viewed with ethidium bromide. Similar results were obtained by RT-PCR analysis for IL-1RI and IL-1RII in hOCs directly isolated from osteopenic bone specimens obtained from 6 patients ( 4 women of 71, 76, 78, and 78 years of age; and 2 men of 56 and 78 years of age) undergoing hip replacement surgery, and a patient with implant osteolysis (a 71-year-old man). St., molecular weight standards. apoptotic rate. In contrast, estrogen had no discernible effect on the IL-1 responses of osteoblast-like cells derived from the same bone marrow cell cultures.

\section{Methods}

Materials. Recombinant human IL-1 $\beta$ (R\&D Systems Inc., Minneapolis, Minnesota, USA) was reconstituted in PBS with $1 \%$ $\mathrm{BSA}$ and stored as aliquots at $-70^{\circ} \mathrm{C}$. Dexamethasone, $17 \beta$ estradiol, and $17 \alpha$-estradiol (all from Sigma Chemical Co., St. Louis, Missouri, USA) were freshly prepared in ethanol at a concentration of $10^{-3} \mathrm{M}$ and further diluted in culture medium for use. Vehicle (ethanol) controls were similarly diluted. 1,25[OH $]_{2}$ vitamin $\mathrm{D}_{3}$, a gift from Hoffman-La Roche (Nutley, New Jersey, USA), was stored dry at $-70^{\circ} \mathrm{C}$ and reconstituted in ethanol before use. Neutralizing antibodies for the IL-1 receptors, antihuman IL-1RII antigen affinity-purified IgG (catalog no. AF263-NA; R\&D Systems Inc.) and anti-human IL-1RI total IgG (catalog no. AB-269-NA; R\&D Systems Inc.), were reconstituted in PBS at $0.1 \mathrm{mg} / \mathrm{mL}$ and $1 \mathrm{mg} / \mathrm{mL}$, respectively. FBS and $\alpha$ MEM were from GIBCO BRL (Gaithersburg, Maryland, USA).

Isolation of OCs from buman bones. Human OCs (hOCs) were isolated from femoral heads obtained as discarded surgical material from osteoporotic patients undergoing hip replacement or from segments of bone removed from sites of implant loosening during resection, using a modification of the methods to isolate and purify avian OCs (46) as described recently $(45,47)$. Briefly, cells were released from small pieces of bone by trypsin and collagenase digestion, and cell cultures were enriched for hOCs by Percoll fractionation. Cells were cultured in phenol red-free medium 199 Earle's salts supplemented with $8.3 \mathrm{mM} \mathrm{NaHCO}_{3}, 100 \mathrm{mM}$ HEPES (pH 6.8), 5\% FBS, and 2.5\% antibiotic/antimycotic for 16-24 hours before harvest for RNA extraction. Highly purified hOC preparations were obtained by immunomagnetic purification with the specific anti-OC $\mathrm{mAb}$ $121 \mathrm{~F}$ (46) and immediately harvested for RNA extraction. Purified hOC cultures consisted of approximately $90 \%$ multinucleated OCs that exhibited all typical osteoclastic attributes, including calcitonin responsiveness and the ability to form resorption pits when cultured on bone or ivory slices.

Isolation and culture of human bone marrow-derived cells and osteoblasts. Bone marrow was obtained from human rib segments discarded during thoracic surgery or from donated iliac crest bone or rib segment derived from individuals with no identified bone pathologies. Marrow mononuclear cells separated by Ficoll-Hypaque density gradients (Pharmacia Biotech Inc., Piscataway, New Jersey, USA) were induced to form multinucleat-

\section{a}
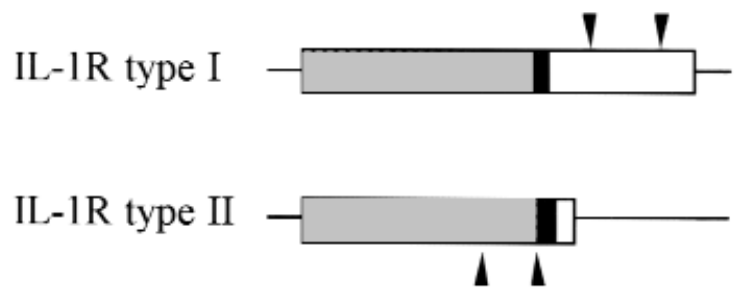

b

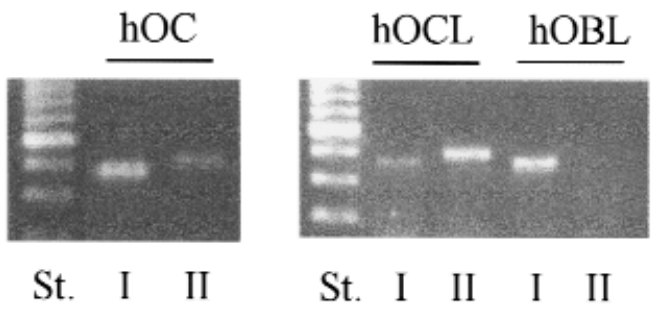




\section{Figure 2}

IL-1 induction of IL-8 in hOCL cells is mediated by the signaling IL-1RI. Bone marrow-derived hOCL cells were preincubated for 1 hour in the absence $(0)$ or presence of neutralizing antibodies to the signaling IL-1RI ( 5 or $50 \mu \mathrm{g} / \mathrm{mL}$ ) or the decoy IL-1RII ( 1 or $5 \mu \mathrm{g} / \mathrm{mL}$ ) at concentrations that represent approximately $1-10$ times their $\mathrm{ND}_{50}$ (antibody concentration required for half-maximal inhibition of IL-1 activity as determined by the manufacturer). Cell cultures were then treated for 16 hours with $10^{-9} \mathrm{M}$ $\mathrm{IL}-1 \beta(+)$ or vehicle $(-)$, and the cells were harvested for protein determination. IL-8 cytokine release was measured in the conditioned medium, normalized by the total cellular protein in each culture dish, and expressed as the mean \pm SEM of nanograms of IL-8 released per milligrams of cell protein. Significant differences from control cultures: ${ }^{*} P<0.01$. Significant differences from IL-1-treated cultures: ${ }^{+} P<0.05$. Determined by Bonferroni post-ANOVA test for multiple comparisons.

ed human OC-like (hOCL) cells by treatment with $10 \mathrm{nM}$ $1,25[\mathrm{OH}]_{2}$ vitamin $\mathrm{D}_{3}$ and osteoblast-conditioned medium as described previously $(43,48)$. Cell preparations were highly enriched for hOCL cells, which were calcitonin receptor positive, by brief trypsinization to remove contaminating stromal cells selectively (43). The remaining purified hOCLs were subsequently detached from the culture dish by further trypsin treatment combined with gentle scraping, and the hOCL cells were replated in phenol red-free $\alpha$-MEM containing 10\% FBS and 1\% antibiotic/antimycotic at $0.3-0.7 \times 10^{6}$ cells per well of a 6 -well culture dish. Human stromal cells were obtained from the same bone marrow mononuclear preparations used for the generation of hOCL cells and were induced to become mineralizing human osteoblast-like (hOBL) cells by treatment with dexamethasone for 6 days according to Cheng et al. (49). Cultures of in vivo-formed human osteoblasts (hOBs) were prepared as trabecular outgrowth cells from surgical specimens of rib bone (50). All cell cultures were given phenol red-free and dexamethasone-free $\alpha$-MEM containing $10 \%$ FBS and $1 \%$ antibiotic/antimycotic at least 24 hours before the addition of fresh medium containing modulators or matched vehicle controls. After the indicated incubation times, conditioned medium was collected, briefly centrifuged, and stored at $-20^{\circ} \mathrm{C}$ until analyzed, and the cells were harvested for RNA extraction.

RNA isolation and analysis. Total RNA was obtained from cells using RNA STAT-60 (Tel-Test Inc., Friendswood, Texas, USA) and was analyzed by the following methods. RT-PCR: cDNA was prepared from $5 \mu \mathrm{g}$ of total RNA using random hexamer primers (cDNA cycle kit; Invitrogen, San Diego, California, USA), and $10-20 \%$ of the cDNA was used for each PCR amplification (30 cycles). Specific primers for PCR were the following: IL-1RI forward, GGTGACAGTAACTGGTGTT; IL-1RI reverse, ACGTTGGGGAAGACATTGTT (from GenBank locus HUMILRA); IL-1RII forward, CAACATCACTAGGAGTATTGA; IL-1RII reverse, CAATGCCCCAGGAGA ACGTGGA (from locus HSIL1R2II); GAPDH forward, ATTCCACCCATGGCAAATTC; and GAPDH reverse, GGCAGAGATGATGACCCT (from locus HUMGAPDHG). RT-PCR products were subcloned into the PCRII vector (TA cloning kit; Invitrogen) and sequenced (Sequenase kit; USB, Cleveland, Ohio, USA). RTPCR amplifications of the estrogen receptor followed the protocol of Arts et al. (51) using the following primers: ER- $\alpha$ forward, AATTCAGATAATCGACGCCAG; ER- $\alpha$ reverse, GTGTTTCAACATTCTCCCTCCTC (from GenBank locus HUMERMCF) at a concentration of $5 \mathrm{nM}$ for the first round of amplification (30 cycles); ER- $\alpha$ forward nested, GACAAGGGAAGTATGGCTATGGA; and the same ER- $\alpha$ reverse at $1 \mu \mathrm{M}$ in the second round ( 30 cycles). The ER PCR amplicons were directly sequenced using an ABI Prism Cycle Sequencing kit (Perkin-Elmer, Foster City, California, USA).

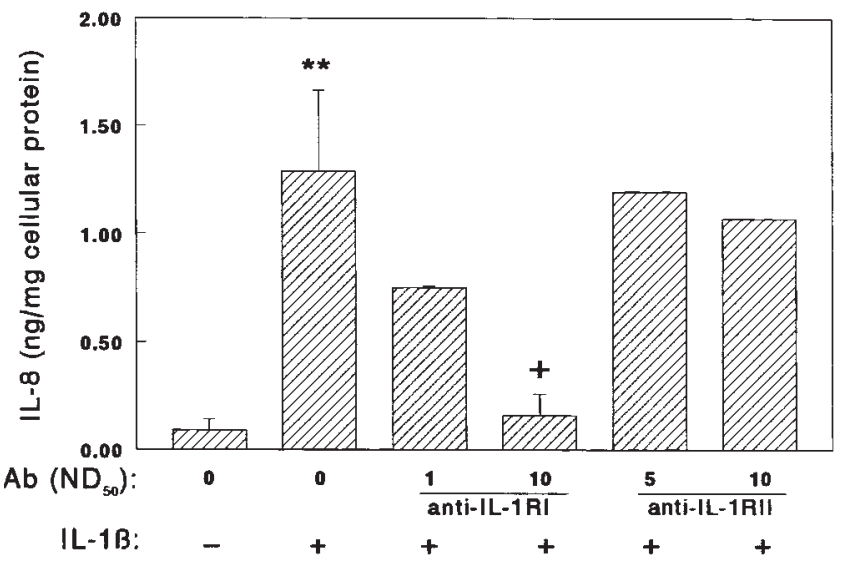

Northern blot analysis. Northern analysis was performed with poly(A)-selected RNA (Oligotex kit; QIAGEN Inc., Chatsworth, California, USA) obtained from $100 \mu \mathrm{g}$ of total RNA. RNA blots were sequentially hybridized with radioactively labeled probes (Random Primers DNA Labeling System; GIBCO BRL) for 18 hours at $42^{\circ} \mathrm{C}$. After extensive washing, hybridized blots were subjected to autoradiographic detection. Blots were stripped between probes when necessary.

Ribonuclease protection assays. RNA probes for ribonuclease protection assays (RPAs) were generated from the IL-1RI and IL1RII PCR clones already described here or from a 406-bp human IL-8 cDNA (kindly provided by S. Kunkel, Department of Pathology, University of Michigan Medical School, Ann Arbor, Michigan, USA), using the in vitro transcription kit MAXIscript (Ambion Inc., Austin, Texas, USA), and were purified in 5\% polyacrylamide/8 $\mathrm{M}$ urea gels. RPA was performed using the RPAII kit (Ambion Inc.) by hybridizing 5-10 $\mu \mathrm{g}$ of total RNA for 18 hours at $45^{\circ} \mathrm{C}$ with $100,000 \mathrm{cpm}$ IL-1RI (511 bp), 100,000 cpm IL-1RII (425 bp), or 20,000 cpm IL-8 (492 bp) probes, together with $20,000 \mathrm{cpm} \mathrm{GAPDH}(259 \mathrm{bp})$. The protected fragments (368 bp IL-1RI, 279 bp IL-1RII, 406 bp IL-8, and $170 \mathrm{bp}$ GAPDH) were separated in $8 \%$ polyacrylamide $/ 8 \mathrm{M}$ urea gels, detected by autoradiography, and quantified in a scanner (ScanJet II; Hewlett-Packard, Palo Alto, California, USA) linked to Quantimet 500 image analysis software (Leica, Cambridge, United Kingdom), or directly quantified in a PhosphorImager (Molecular Dynamics, Sunnyvale, California, USA), yielding comparable results.

Quantification of IL-8 and sIL-1RII release. IL-8 or sIL-1RII levels in the conditioned media of hOCL and hOBL cell cultures were measured by ELISA using Quantikine kits (R\&D Systems Inc.) following the manufacturer's specifications. IL-8 and sIL-1RII release was normalized to cellular protein in the culture dish based on the bicinchoninic acid (BCA) assay (Pierce Chemical Co., Rockford, Illinois, USA). Alternatively, sIL-1RII release into the conditioned medium was expressed in relation to the total RNA obtained from the culture dish.

Apoptosis assay. Highly enriched hOCL cells were cultured on glass coverslips in phenol red-free $\alpha$-MEM con-

\section{Table 1}

Comparison of the steady-state IL1RII/IL-1RI mRNA ratios (II/I) in bone marrow-derived hOCL cells relative to the age and gender of the donor

\begin{tabular}{llcc}
\multicolumn{2}{c}{ Women } & \multicolumn{2}{c}{ Men } \\
Age (years) & II/I & Age (years) & II/I \\
51 & 2.7 & 40 & 1.33 \\
53 & 3.3 & 40 & 5.1 \\
56 & 3.0 & 53 & 0.62 \\
58 & 2.1 & 54 & 0.77 \\
60 & 1.4 & 54 & 4.46 \\
61 & 3.1 & 57 & 1.08 \\
62 & 0.85 & 58 & 1.5 \\
63 & 0.58 & 60 & 0.5 \\
67 & 1.47 & 63 & 1.3 \\
69 & 0.38 & 63 & 3.3 \\
72 & 0.32 & 68 & 3.5
\end{tabular}


a

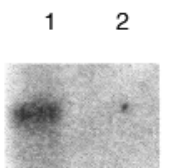

IL-1RI

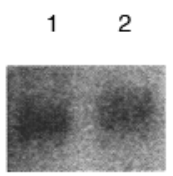

IL-1RII

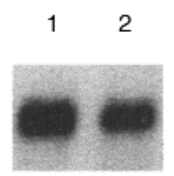

GAPDH

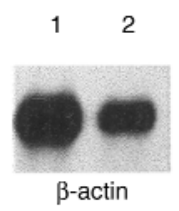

b

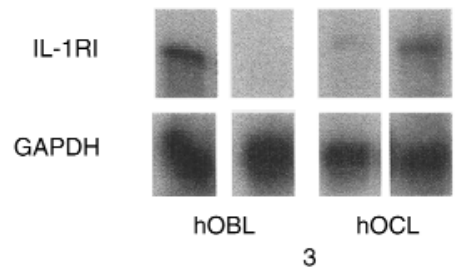

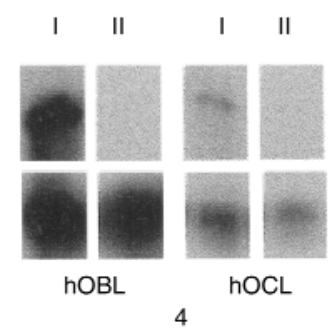

Figure 3

Steady-state mRNA levels for IL-1RI and IL-1RII vary among hOCL cells generated from different donors. (a) Northern analysis of poly(A)-selected RNA from hOCL cells derived from 2 different individuals (designated 1 and 2) sequentially hybridized with the indicated probes. Transcripts were identified of the following approximate sizes: $5.6-\mathrm{kb}$ IL-1RI, 1.4-kb IL-1RII, 1.4-kb GAPDH, and 2.0-kb $\beta$-actin. Amounts of each radioactive probe used and times of gel exposure for autoradiography were as follows: IL-1RI, $3 \times 10^{6} \mathrm{cpm} / \mathrm{mL}, 7$ days; IL-1RII, $3 \times 10^{6} \mathrm{cpm} / \mathrm{mL}, 14 \mathrm{days}$; GAPDH, $2 \times 10^{6} \mathrm{cpm} / \mathrm{mL}, 20 \mathrm{hours}$; and $\beta$-actin, $1 \times 10^{6} \mathrm{cpm} / \mathrm{mL}, 60$ hours. (b) Representative RPA for IL-1RI and IL-1RII using total RNA from hOCL and hOBL cells that were obtained from the same bone marrow mononuclear cultures of 2 different individuals (designated 3 and 4 ). Each sample was probed simultaneously with IL-1RI (I) and GAPDH, or in a parallel reaction with IL-1RII (II) and GAPDH. To attribute correctly the protected bands as signals for IL-1RI, IL-1RII, and GAPDH, reactions were first performed with each individual probe alone. Specific protected bands were of the expected sizes, which differed from one another, and were clearly discernible from full-length unprotected probes (which were included along with molecular size markers in the gels). The data shown in $\mathbf{b}$ were obtained from a single RPA and set of labeled probes. Additional RPAs performed with hOCL cells derived from 25 other donors yi elded similar variations in their relative steady-state mRNA levels of the 2 IL-1Rs, a feature inherent to the hOCL cell preparations themselves (see Fi gure 4).

taining $10 \%$ charcoal-stripped FBS and $1 \%$ antibiotic/antimycotic, and treated with the various modulators (see the legend for Figure 7) for a total of 22 hours. Attached cells were then washed 3 times with warm HBSS and stained for 12 minutes in the dark using annexin $\mathrm{V}$-fluorescein (to stain apoptotic and necrotic cell membranes) combined with propidium iodide (to stain only necrotic cell nuclei) as provided in a kit (Boehringer Mannheim Biochemicals, Indianapolis, Indiana, USA). Coverslips were mounted with buffered glycerol mounting medium (BBL 40825, Becton Dickinson, Cockeysville, Maryland, USA) supplemented with $5 \mathrm{mM} \mathrm{CaCl}_{2}$, and labeled cells were viewed and counted by fluorescence microscopy. Annexin-stained cells from 3-5 independent cell cultures derived from 2 different bone marrow donors were evaluated across 10-16 fields, encompassing a total of 2,400-3,700 hOCL for each control or experimental condition.

Statistical analysis. Data are presented as the mean \pm SEM of at least 3 independent replicate cell cultures. Differences between treatments were analyzed using single-factor ANOVA. For simultaneous comparisons between multiple treatments, significant differences were determined using the post-ANOVA Bonferroni test. Differences were considered significant for $P<0.05$.

\section{Results}

hOC and hOCL cells express $m R N A$ for both IL-1RI and IL-1RII. IL-1 receptor mRNA expression in hOC and hOCL cells was analyzed by RT-PCR using specific oligonucleotides designed to recognize unique regions of the human IL-1RI and IL-1RII genes (Figure 1a). In vivo-formed bone-resorptive hOCs directly isolated from human bones, as well as multinucleated hOCL cells differentiated in vitro from human bone marrow-derived mononuclear cells, expressed mRNA for both the signaling IL-1RI and the decoy IL-1RII. In contrast, bone marrow-derived stromal cells (not shown) and stromal-derived hOBL cells, cell types that are unrelated to the hematopoietic lineage, expressed mRNA for the signaling IL-1RI but undetectable levels of the decoy IL-1RII (Figure 1b). Because hOCL cells exhibit multiple OC phenotypic characteristics and, like hOC, expressed mRNA for both the signaling and decoy IL-1Rs, further studies to investigate potential regulation of these
IL-1Rs were performed using hOCL cells, which are more readily available in larger numbers and are easier to purify from contaminating cells than hOCs.

bOCL cells express functional IL-1RI and release sIL-1RII to the media. Previously, we showed that hOCL cells responded dose dependently to IL-1 with increases in IL- 8 mRNA and protein production. Here we determined that this hOCL cell response to IL- 1 was mediated by the signaling IL-1RI because the IL- $1 \beta$-induced accumulation of IL- 8 in the conditioned medium of hOCL cell cultures was inhibited by an IL-1RI neutralizing antibody, but not by similar doses of a neutralizing antibody to the decoy IL1RII (Figure 2). Thus, hOCL cells contain functional signaling IL-1RI in their plasma membrane. In addition, hOCL cells also expressed IL-1RII protein based on immunodetection of sIL-1RII in the conditioned media of the same cell cultures ( $8 \mathrm{ng}$ sIL-1RII/mg of cellular protein). These results indicate that hOCL cells not only express both IL-1R mRNAs, but also synthesize IL-1RI and IL-1RII proteins and functionally respond to IL-1.

Relative steady-state $m R N A$ levels for IL-1RI and IL-1RII in hOCL cells vary among bone marrow donors. Evaluation of the mRNA levels for each IL-1R subtype in hOCL cell cultures derived from 28 independent bone marrow donors by Northern or RPA analysis, using IL-1R probes generated from RT-PCR amplicons, revealed substantial differences in the relative expression levels of the 2 IL$1 \mathrm{R}$ transcripts. Thus, whereas these probes identified mRNA of the expected size in Northern analyses of 2 independent hOCL cell cultures, the relative steadystate levels of the 2 IL-1R transcripts were quite different (Figure 3a). A similar variation in the relative levels of these IL-1R mRNA species was also detected by RPA for hOCL cell cultures obtained from other independent bone marrow donors (Figure $3 \mathrm{~b}$ ). By contrast, hOBL cell cultures generated from some of these same bone marrow mononuclear preparations consistently expressed relatively high levels of IL-1RI mRNA and undetectable levels of IL-1RII mRNA, as analyzed either 
by RPA (Figure $3 \mathrm{~b}$ ) or by RT-PCR (Figure 1 ). The steadystate levels of IL-1RII mRNA in the various cell preparations correlated well with the amount of sIL-RII measured in their conditioned medium. Therefore, whereas independent hOCL cell cultures exhibited variable levels of sIL-RII that ranged from 7 to 400 pg sIL-1RII accumulated in the conditioned medium after 4-8 hours of culture per microgram of total RNA (mean: $92.6 \pm 35.8$ [SEM]; $n=12$; median: 48.35 ; $95 \%$ confidence interval [CI]: $13.7,171.5)$, sIL-1RII was undetectable in the conditioned media of bone marrow-derived hOBL cells or hOB isolated from bone segments that were cultured for similar times.

$I L-1 R I I / I L-1 R I m R N A$ ratios in hOCL cells correlate with the age and gender of the bone marrow donor. RPA analysis of IL$1 \mathrm{R}$ mRNA relative levels was performed in hOCL cells derived from bone marrow mononuclear preparations of 22 different donors over the age of 40 , and the results were expressed as the ratio IL-1RII/IL-1RI mRNA (Table 1 ). Analysis of the data revealed that, even for the limited number of cases available to test $(n=11)$, there was a statistically significant $(P=0.002)$ inverse linear correlation $(r=-0.81)$ between the levels of the decoy IL-1RII mRNA relative to those of the signaling IL-1RI and increasing age of the female donor (Figure 4a). Therefore, hOCL cells from older women in the postmenopausal period (over 60 years old) had equivalent or lower mRNA levels for the decoy IL-1RII compared with the signaling IL-1RI, whereas hOCL cells from younger women in the perimenopausal or early postmenopausal periods had significantly higher mRNA steady-state levels for the decoy IL-1RII compared with the signaling IL1RI. Similar to mRNA levels, sIL-1RII protein levels measured in the conditioned medium of hOCL cells derived from female bone marrow donors $(n=5)$ were also inversely correlated $(r=-0.86)$ with the age of the female donors, although this did not quite reach significance $(P=0.06)$ in this small sample group. These findings suggested that the declining levels of estrogen in postmenopausal women might influence the steadystate levels of IL-1R mRNAs and sIL-1RII released from cultured bone marrow-derived hOCL cells obtained from female donors. This inverse correlation between relative IL-1R mRNA levels and age was not observed among the same number $(n=11)$ of hOCL cell cultures obtained from male donors of approximately the same age range. To the contrary, no correlation $(r=0.15, P=$ 0.66 ) was obtained between IL-1R mRNA ratios and age of the male donor (Figure 4b).

Estrogen decreases signaling IL-1RI while increasing decoy IL1RII mRNA levels in cultured hOCL cells. Most bone marrow was obtained from accident victims; therefore, information on the donor estrogen status was not available for direct comparison with IL-1R mRNA ratios in the generated hOCL cells. The hypothesis that estrogen might differentially influence IL-1R mRNA levels in hOCL cells was directly investigated in vitro. First, RT-PCR analysis was performed to demonstrate that the marrow-derived hOCL cells used in this study, as well as authentic hOCs directly isolated from human bones, expressed mRNA for ER- $\alpha$ (Figure 5a). We then tested whether 17ß-estradiol could regulate the steady-state mRNA levels for IL-1RI and IL- $\mathbf{a}$

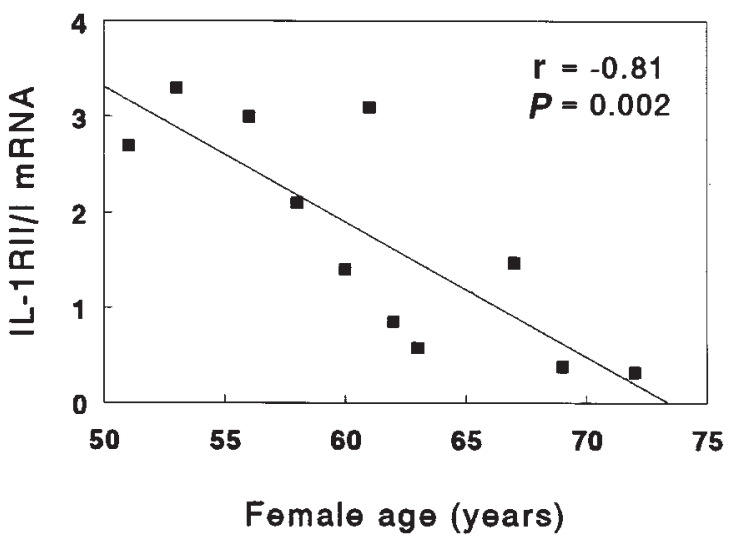

b

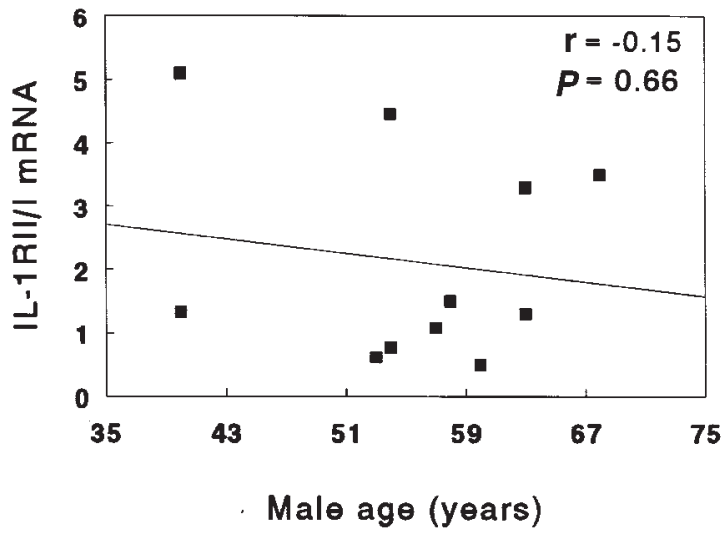

Figure 4

IL-1RII/IL-1RI steady-state mRNA ratios in hOCL cells decrease with increasing age of female, but not male, bone marrow donors. Steadystate mRNA levels for IL-1RI, IL-1RII, and the internal control GAPDH were measured in hOCL cells generated from 11 women ranging from 51 to 72 years of age (a), and from 11 men ranging from 40 to 68 years of age (b), as described in Figure $3 \mathrm{~b}$. No bone marrow samples were available from female donors of 40 to 50 years of age. The IL-1RII/IL-1RI mRNA ratios were calculated as follows: the signal intensity of each IL$1 \mathrm{R}$ protected band was divided by the signal intensity of the corresponding internal GAPDH control for that reaction, and the normalized value for IL-1RII was then divided by the normalized value for IL-1RI (Table 1). $P$, statistical significance as determined by ANOVA; $r$, correlation coefficient. Typically, as many RNA samples as possible were run in a single RPA (using the same gel and probes) to enable direct comparisons. In addition, RNA obtained from 2 different hOCL cell cultures each was reanalyzed in 3 separate RPA trials to calculate the variances associated with determining the IL-1RII/IL-1RI mRNA ratios across independent RPA experiments. Thus, independent assessments of the IL-1RII/IL-1RI ratio for hOCL cells derived from a 72-year-old woman yielded values of 0.28 , 0.3 , and 0.32 with a variance of 0.0004 , and hOCL cells from a 51 -yearold woman yielded ratios of 2.4, 1.8, and 2.0 with a variance of 0.093 .

1RII measured by RPA in hOCL cells cultured with or without $17 \beta$-estradiol for 4 hours. $17 \beta$-estradiol dose dependently inhibited the steady-state mRNA levels of the signaling IL-1RI while stimulating those of the decoy IL1RII (Figure 5, b-d). Thus, treatment with $10^{-7} \mathrm{M} 17 \beta$ estradiol, but not with the same concentration of the inactive analogue $17 \alpha$-estradiol, caused a statistically significant reduction of $\sim 30 \pm 7 \%$ in the steady-state levels 
a

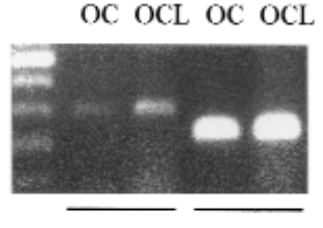

St. $\mathrm{ER} \alpha \mathrm{GAPDH}$

d

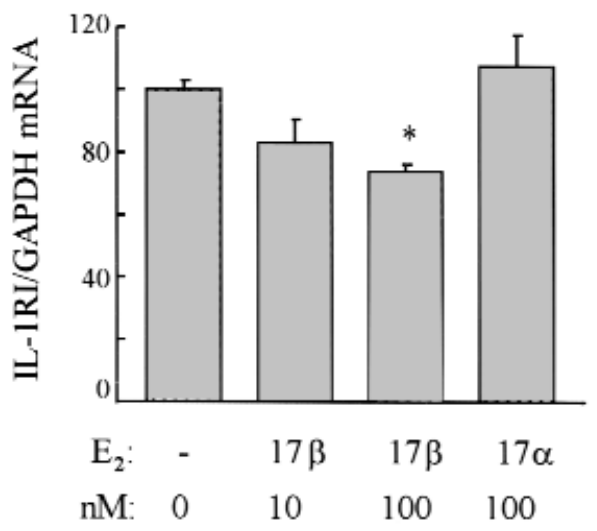

C

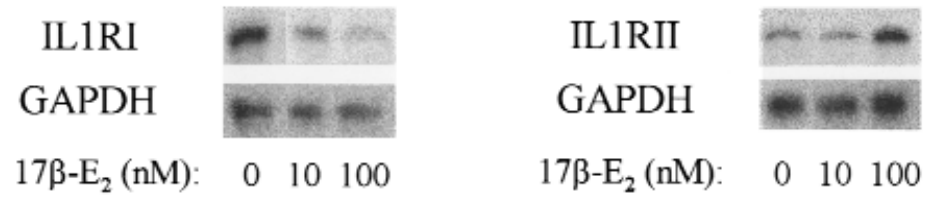

e

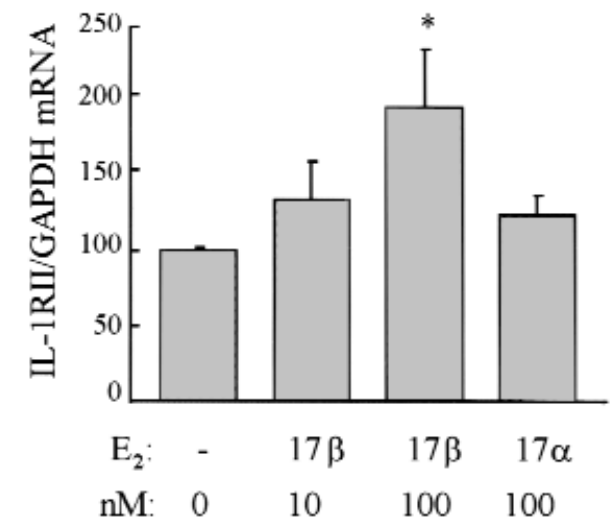

Figure 5

$17 \beta$-estradiol differentially regulates IL-1RI and IL-1RII mRNA levels in hOCL. (a) hOC and hOCL cells express mRNA for ER- $\alpha$. RT-PCR analysis of ER- $\alpha$ and GAPDH was performed using total RNA of immunomagnetically purified hOC directly isolated from a femoral head or from purified bone marrow-derived hOCL cells. Amplicons were separated in 1.5\% agarose gels and stained with ethidium bromide. (b-e) $17 \beta$-estradiol decreased signaling IL$1 \mathrm{RI}$ and increased decoy IL-1RII mRNA levels in hOCL cells. hOCL cell cultures derived from 5 different bone marrow donors ( 2 women and 3 men, 1 to 3 replicate wells each) were incubated for 4 hours with vehicle (0), 10 or $100 \mathrm{nM} 17 \beta$-estradiol ( $\left.E_{2}\right)$, or $100 \mathrm{nM}$ of the inactive analogue $17 \alpha$-estradiol. Total RNA was extracted, and steady-state mRNA levels for IL-1RI, IL-1RII, and GAPDH were measured by RPA. (b and $\mathbf{c}$ ) Representative RPA for IL-1RI and GAPDH mRNA (b), and for IL-1RII and GAPDH mRNA (c). (d and e) Protected IL-1R mRNA bands were quantified and normalized to GAPDH. The data are expressed as a percentage of vehicle control and represent the mean \pm SEM of the IL-1RI/GAPDH ratio (d) or the IL-1RII/GAPDH ratio (e). Significant differences from control cultures: ${ }^{*} P<0.05$ as determined by Bonferroni post-ANOVA test for multiple comparisons. St., molecular weight standards.

of IL-1RI mRNA, together with a significant increase to $\sim 200 \pm 40 \%$ of control levels in the steady-state expression of IL-1RII mRNA. Similar responses occurred in hOCL cells generated from the bone marrow of either female or male donors. Furthermore, treatment of hOCL cells $(n=$ 6 from 4 independent bone marrow donors) for 8 hours with $10^{-7} \mathrm{M} 17 \beta$-estradiol caused a significant increase $(50 \%, P=0.045)$ in the levels of sIL-1RII released into the conditioned medium (mean ratio of estrogen-treated to control cultures was $1.504 \pm 0.213$ [SEM]; median: 1.42; 95\% CI: $0.987,2.317$; variance: 0.274$)$. In contrast to hOCL cells, $17 \beta$-estradiol did not modify either the steady-state levels of IL-1RI or IL-1RII mRNA in 3 independent stromal-derived hOBL cell or hOB cultures.

Estrogen pretreatment suppresses the $I L-1$ responsiveness of bOCL, but not hOBL, cells. To test whether estrogen-induced alterations in the IL-1R mRNA levels of hOCL cells had physiological consequences relative to their ability to respond to IL-1, hOCL cell cultures were preincubated for 4 hours with $17 \beta$-estradiol $\left(10^{-7} \mathrm{M}\right)$ or vehicle before being challenged with IL-1 $\beta\left(10^{-9} \mathrm{M}\right.$, 4 hours $)$, and the levels of IL-8 mRNA were assessed as a sensitive reflection of IL-1 responsiveness. $17 \beta$-estradiol alone did not alter the basal steady-state levels of IL- 8 mRNA in hOCL cells, whereas incubation with IL-1 resulted in a typical $\sim 3$-fold increase in IL-8 mRNA levels. However, pretreatment with $17 \beta$ estradiol diminished the IL-1 responsiveness of hOCL cells by $\sim 60 \%( \pm 2.7$ SEM), as reflected in IL-8 mRNA induction (Figure 6a). Furthermore, we noted that the magnitude of the estrogen inhibitory effect was inversely correlated with the levels of decoy IL-1RII in 3 bone marrow preparations from which sufficient numbers of hOCL cells were generated to permit multiple analyses. Thus, IL1RII/IL-1RI mRNA ratios (3.1, 1.5 , and 0.2 , respectively) and sIL-1RII release $(400,41$, and $6 \mathrm{pg} / \mu \mathrm{g}$ RNA, respectively) in these 3 hOCL cell preparations were inversely correlated with IL-1 responsiveness (1.87-, 2.02-, and 4.9fold IL-8 mRNA induction, respectively), estrogen stimulation of sIL-1RII release (1.05-, 1.2-, and 1.85-fold increase, respectively), and estrogen inhibition of IL1-induced IL-8 mRNA (31\%, 44\%, and 53\% inhibition, respectively). Parallel studies showed that stromal-derived hOBL cells and primary hOBs, both of which were shown to express only signaling IL-1RI mRNA, also responded to IL-1 treatment with an induction of IL-8 mRNA of $\sim 4.5$ fold over control, but they were insensitive to the inhibitory action of $17 \beta$-estradiol pretreatment on IL-8 mRNA levels (Figure 6d). Further studies to document the estrogen inhibition of hOCL cell IL-1 responsiveness were performed based on annexin V-fluorescein labeling of apoptotic cells. hOCL cell cultures were pretreated with vehicle or $17 \beta$-estradiol $\left(10^{-7} \mathrm{M}\right.$, 4 hours) before being challenged with IL-1 $\beta\left(10^{-9} \mathrm{M}, 18\right.$ hours $)$ and stained for annexin V binding. The proportion $(5.2 \% \pm 0.67$ [SEM] $)$ of apoptot- 
ic hOCL cells present in control cultures was not significantly affected by $17 \beta$-estradiol alone, but it was significantly decreased ( $\sim 60 \%$ ) by IL-1 treatment. However, $17 \beta$ estradiol pretreatment of hOCL cells before IL-1 exposure fully inhibited $(P<0.05)$ the cell survival effects of IL-1 (Figure 7). This effect was not observed using the inactive analogue $17 \alpha$-estradiol (not shown). Thus, estrogeninduced modulation of IL-1RI and IL-1RII mRNA levels is associated with inhibitions in 2 independent functional measures of IL-1 biologic responsiveness in hOCL cells.

\section{Discussion}

We have shown here for the first time to our knowledge that (a) highly purified authentic human bone-resorptive hOCs and closely related bone marrow-derived hOCL cells formed in vitro express mRNA for both the signaling (type I) and decoy (type II) IL-1 receptors; (b) the signaling receptor mediates IL- 1 responsiveness in hOCL cells; (c) the steady-state mRNA levels for these 2 receptors are differentially expressed in vivo as a function of increasing female donor age, or in vitro in response to estrogen in hOCL cells; and (d) such estrogen regulation is associated with altered IL-1-mediated biologic responses. Therefore, estrogen increased sIL-1RII secretion and steady-state mRNA levels for the decoy IL-1RII while decreasing those for the signaling IL-1RI in hOCL cells, and this was associated with reduced IL-1-mediated cytokine induction and cell survival responses. We surmise that estrogen regulation of IL-1R levels and IL-1 responsiveness in hOC and hOCL cells may represent an important novel mechanism contributing to the boneprotective effects of estrogen. Conversely, declining levels of circulating estrogen in menopause may enhance the antiapoptotic and proresorptive effects of IL-1 on OCs.

IL-1 is locally elevated in pathological disorders associated with bone loss and is a potent stimulator of bone resorption and OC differentiation and activity (34). However, most IL-1 effects on OC have been attributed to indirect actions mediated by other bone cell types. We have shown here that hOC and hOCL cells derived from human bones express mRNA for both IL-1RI and IL$1 \mathrm{RII}$ and that IL-1RI mediates IL-1 responses in hOCL cells. Therefore, hOC cells may also serve as direct targets for IL-1 actions in vivo. Like these primary human cells, both IL-1R isoforms have been detected in OCs of mouse and rat bones (41). Furthermore, the 2 IL-1Rs were differentially expressed in bones from arthritic rats exhibiting significant bone destruction: large numbers of resorbing OCs were present that all expressed high IL$1 \mathrm{RI}$ and very low IL-1RII mRNA levels compared with normal animals (41). Similarly, we found that active bone-resorptive primary hOC cells, isolated from a

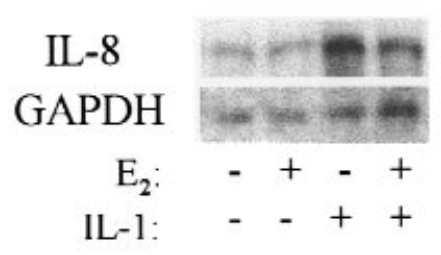

b

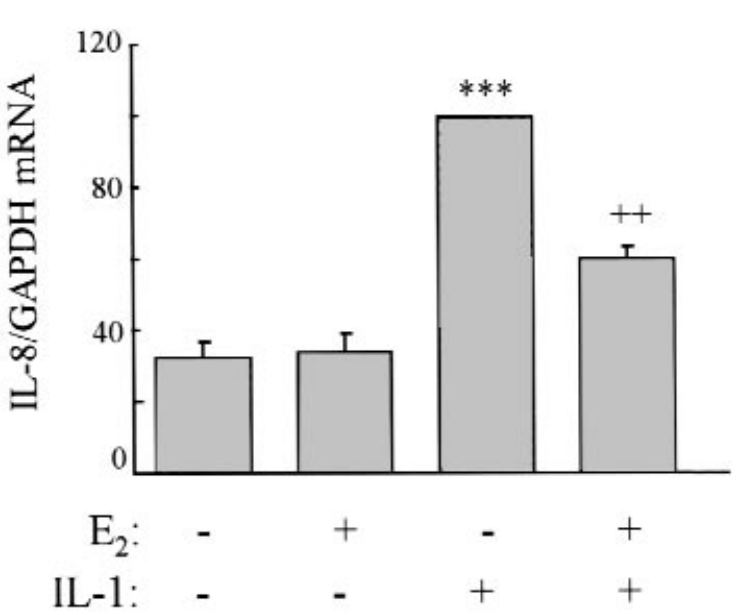

C

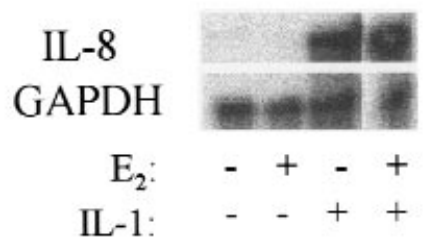

d

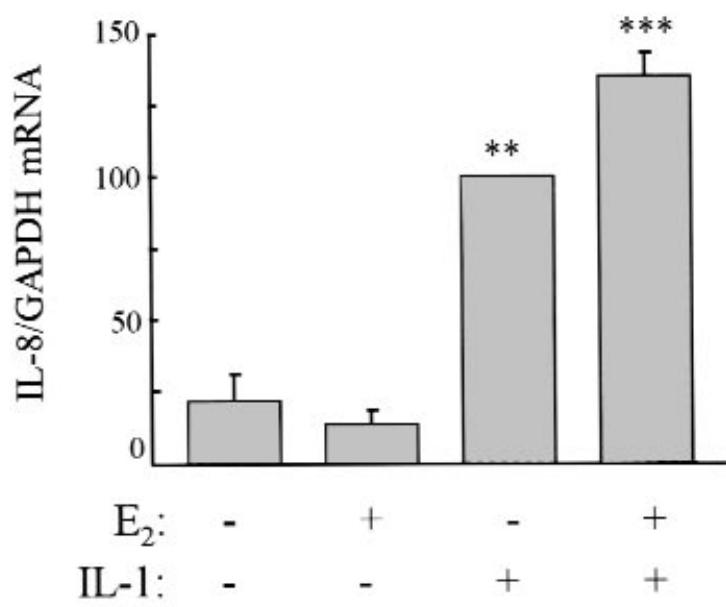

Figure 6

$17 \beta$-estradiol pretreatment of hOCL cells, but not hOBL cells, inhibits IL-1 induction of IL-8 mRNA. hOCL cells (a and b) or hOBL cells (c and d) were preincubated for 4 hours with $10^{-7} \mathrm{M} 17 \beta$-estradiol $\left(E_{2},+\right)$ or vehicle $(-)$. After pretreatment, the same modulators were added to the cell cultures simultaneously with $10^{-9} \mathrm{M} \mathrm{IL}-1 \beta(\mathrm{IL}-1,+)$ or vehicle $(-)$, and the cells were further incubated for another 4 hours. Total RNA was extracted, and IL-8 mRNA was analyzed by RPA as a functional measure of IL-1 biologic responsiveness. (a and c) Representative RPA for IL- 8 mRNA levels in hOCL and hOBL, respectively. ( $\mathbf{b}$ and $\mathbf{d}$ ) IL-8 mRNA protected bands from 3 independent hOCL (b) or hOBL (d) cell cultures were quantified and normalized to GAPDH. Additional results obtained using a primary hOB cell culture were indistinguishable from those obtained with the hOBL cell cultures. Data are expressed as a percentage of maximal IL- 8 mRNA levels induced by IL-1 $\beta$ and represent the mean \pm SEM. Significant differences from control cultures: ${ }^{*} P<0.01,{ }^{*} * P$ $<0.001$. Significant differences from IL-1 $\beta$-treated cultures: ${ }^{++} P<0.01$ as determined by the Bonferroni post-ANOVA test. 


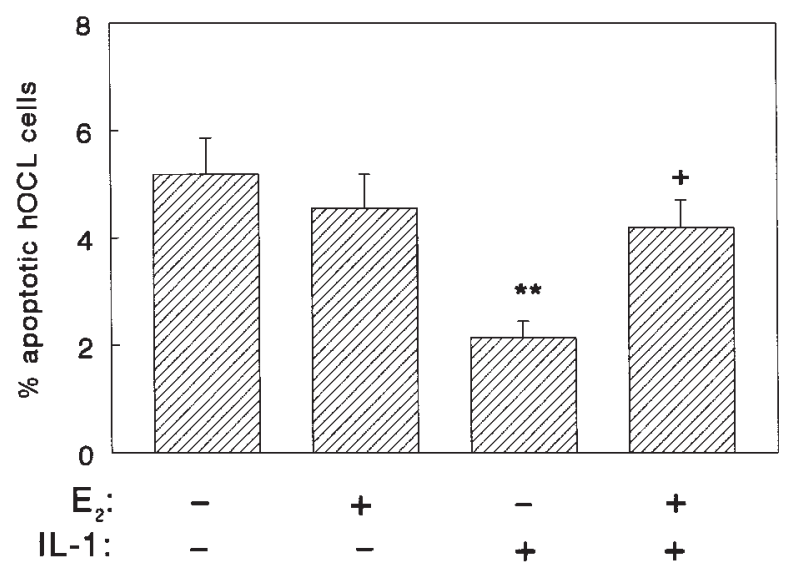

Figure 7

$17 \beta$-estradiol pretreatment of hOCL cells inhibits IL-1-promoted cell survival. hOCL cells cultured on glass coverslips were preincubated for 4 hours with $10^{-7} \mathrm{M} 17 \beta$-estradiol $\left(E_{2},+\right)$ or vehicle (-). After pretreatment, the same modulators were added to the cell cultures simultaneously with $10^{-9} \mathrm{M} \mathrm{IL}-1 \beta(\mathrm{IL}-1,+)$ or vehicle $(-)$, and the cells were further incubated for another 18 hours. hOCL cells were then stained with annexin $\mathrm{V}$-fluorescein to identify apoptotic cells, and a total of 2,400-3,700 hOCL cells for each experimental condition were viewed in 10-16 fields and counted by fluorescence microscopy. Data are expressed as the mean \pm SEM percentage of annexin $\mathrm{V}$-labeled apoptotic $\mathrm{hOCL}$ cells relative to total hOCL cells per field for each condition. No necrotic cells (stained with propidium iodide) were detected in these cultures. Significant differences from control cultures: ${ }^{*} P<0.001$. Significant differences from IL1-treated cultures: ${ }^{+} P<0.05$.

osteopenic bone removed from elderly patients undergoing hip replacement surgery, expressed high IL-1RI and very low IL-1RII mRNA levels. Therefore, increased OC responsiveness to IL-1 may constitute an important underlying mechanism contributing to the osteopenia of various pathological bone disorders.

Whereas hOC cells directly isolated from osteopenic bones of older patients consistently exhibited high IL-1RI and very low IL-1RII mRNA levels, the relative mRNA expression ratio for these receptors in hOCL cells varied with the age and gender of the bone marrow donor. Specifically, the IL-1RII/IL-1RI mRNA ratio decreased with increasing age of the female donor, whereas variations in such ratios were unrelated to age of the male donor. This suggested that declining estrogen levels after menopause (52) might be involved in regulating IL-1R levels in female-derived hOCL cells. Potential estrogen modulation of IL-1R mRNA levels and IL-1 actions in hOCL cells was directly tested in vitro, as hOC and hOCL cells both express ER and respond to estrogen (5-9). Our findings demonstrate for the first time to our knowledge that estrogen inversely regulates steady-state mRNA levels for the signaling and decoy IL-1Rs, thereby increasing IL1RII/IL-1RI mRNA ratios and stimulating sIL-1RII protein secretion by hOCL cells. Estrogen similarly regulated IL-1R mRNA levels in hOCL cells from female or male donors, indicating no inherent gender differences in their ability to respond to estrogen. Given that estrogen levels do not decline with age in men like they do in postmenopausal women and that IL-1RII/IL-1RI ratios did not vary here as a function of male donor age, this ratio may reflect estrogen-mediated regulation of bone metabolism rather than age-related changes in bone mass. Estrogen modulation of IL-1R mRNA levels was selective for hOCL cells among the bone cell types examined. None of the primary hOBs, hOBLs, or human marrow stromal cells obtained from the same bone specimens expressed detectable IL-1RII mRNA, released measurable amounts of sIL-1RII, or exhibited altered IL-1R mRNA levels (or IL1 responses) after estrogen treatment.

Estrogen regulation of gene expression usually involves the estrogen receptor element (ERE) in the promoter of inducible genes. However, estrogen-dependent gene activation can also be mediated by ERE containing some mismatches to the canonical ERE half-site (53), or from AP1 (54) and SP1-like elements (55), sequences present in the IL-1RI promoter (56). This promoter also contains an NF- $\mathrm{KB}$ site (57) that may mediate IL-1RI mRNA downregulation by estrogen, as ER can interact with NF$\kappa \mathrm{B}$ proteins to repress NF- $\kappa \mathrm{B}$-activated genes $(58,59)$. Less is known about regulatory elements, including potential ER responsive sites, within the IL-1RII promoter (60). Changes in IL-1Rs are best monitored by measuring IL-1 responses in cells because both IL-1RI and IL-1RII bind IL-1 with high affinity, IL-1RI is typically expressed at very low levels on primary cells, and occupation of only $2-3 \%$ of the IL-1RI can evoke biologic responses (44). We therefore investigated whether estrogen regulation of IL-1R mRNA altered sIL-1RII protein release and IL-1 physiological responses in hOCL cells. Soluble IL-1RII is elevated in the serum of patients with inflammatory diseases and binds IL- $1 \beta$ with high affinity, thereby functioning as an endogenous antiinflammatory inhibitor of IL-1 action. Our results demonstrated that sIL-1RII protein released by hOCL cells directly paralleled IL-1RII mRNA levels, declining as the age of the female donor increased and rising in response to estrogen. Moreover, increased sIL-1RII levels correlated with decreased responsiveness of hOCL cells to IL-1. Therefore, like other anti-inflammatory agents (61), estrogen may help dampen inflammatory responses by modulating sIL-1RII levels.

The physiological impact of estrogen-mediated IL-1R changes on IL-1 responsiveness in hOCL cells was evaluated using 2 independent assays: induction of the inflammatory chemokine IL-8 and alterations in IL-1-mediated cell survival. Estrogen pretreatment significantly inhibited both IL-1 responses, suppressing IL-1-mediated IL-8 mRNA induction and IL-1-promoted hOCL survival. Previous reports showed that IL-8 is released at high levels by hOC (43); OC-derived IL-8 inhibits multiple osteoblast bone formative functions (42); IL-8 stimulates OC migration $(62,63)$; and IL-8 promotes OC recruitment, development, and bone-resorptive activity together with neoangiogenesis in vivo in a chicken egg model (64). Thus, estrogen may also affect bone remodeling by influencing IL-1-mediated regulation of IL-8. Apoptosis was also evaluated because IL-1 has extended mouse OClike (OCL) cell survival, leading to increased OCL cell numbers and prolonged bone resorption $(37,40)$. Similarly, IL-1 significantly increased hOCL cell survival. However, estrogen pretreatment of hOCL cells complete- 
ly inhibited the prosurvival effects of IL-1. Apoptotic changes of the small magnitude seen here have had important physiological consequences in various tissues, including bone. For example, increasing the percentage of apoptotic OC by as little as $1-2 \%$ in vivo in response to estrogen increased the bone volume of both sham-operated and ovariectomized (OVX) mice 2.5- to 4-fold (65). Estrogen prevention of IL-1-promoted OC cell survival may therefore represent a novel mechanism through which estrogen functions to preserve bone mass.

The estrogen concentrations $\left(10^{-8}\right.$ and $\left.10^{-7} \mathrm{M}\right)$ required here to downregulate IL-1RI mRNA and alter biologic responses in hOCL cells were higher than estrogen circulating levels in premenopausal women $\left(10^{-10}\right.$ to $\left.10^{-9} \mathrm{M}\right)$, although such responses were specific (the inactive isomer $17 \alpha$-estradiol was ineffective). Because the affinity of $17 \beta$-estradiol for its receptor is in the nanomolar range, estrogen has been commonly administered in vitro at $\geq 10^{-8} \mathrm{M}$ to achieve receptor saturation, leading to rapid and maximal effects (7). Although physiological estrogen concentrations have modulated lysosomal enzyme levels, TGF- $\beta$ production, and bone resorption in isolated OCs from mice (65), rabbits (8), and chick hatchlings (10, 66, 67), higher estrogen levels have been required to modulate hOC or hOCL cells $(68,69)$. Possibly, high estrogen concentrations may be needed to influence hOCL cells in vitro, as hOCL cells, in marked contrast to hOBs, can create a proestrogenic local microenvironment, reaching as high as 10-fold serum midcyclic estradiol peaks, independent from actual circulating levels of estrogen (70). Therefore, OCs in vivo may normally experience relatively high estrogen levels.

Our observations suggest that a decline in circulating estrogen levels may contribute to the reduced IL-1RII/IL1RI mRNA ratios observed in hOCL cells generated from women of advanced postmenopausal age. Recent animal studies further support this view. Mice deficient in IL-1RI, although showing normal histomorphometric parameters for long bones (71), exhibited no significant loss of trabecular bone mass after OVX and were therefore protected from estrogen-deficient bone loss (72). In another study, OVX of normal mice decreased IL-1RII mRNA levels in freshly isolated murine bone marrow and calvarial cells, an effect that was reversed by in vivo estrogen replacement (73). Together, the reports indicate that IL-1 signaling through IL-1 receptors plays a key role in mediating estrogen-deficient bone loss in mice, and therefore that the balance in the ratio of IL-1RI relative to IL-1RII may be an influential determinant of bone-remodeling physiology regulated by estrogen. The findings also provide a possible explanation for previous observations that IL-1 activity (measured by bioassay), rather than IL-1 levels (measured by ELISA or immunoradiometric assay), increased in women after OVX $(14,74)$. In conclusion, this study represents the first demonstration $t$ o our knowledge that estrogen inversely regulates IL-1Rs by reducing IL-1RI and elevating IL-1RII mRNA and sIL-1RII release, thereby altering IL-1 bioresponsiveness. We propose that estrogen-mediated regulation of hOCL IL-1Rs represents a novel pathway not described previously for estrogen protection against the proinflammatory and proresorptive actions of IL-1, contributing to a preservation of bone mass.

\section{Acknowledgments}

The authors thank Louis Avioli, Len Rifas, Linda Halstead, and Aurora Fausto for providing the source of human bone marrow cells; William Maloney and Gary Miller for providing the source of human OCs; Fred Anderson for his help in preparing human cell cultures; and Linda Rothe for measuring IL-8 in the conditioned media of cell cultures. This work was supported by National Institutes of Health grants R03 DE-11166-02 (to T. Sunyer) and R01 AG-1543, R01 AR-32087, and RO1 DE-06891 (to P. Osdoby).

1. Turner, R., Riggs, B., and Spelsberg, T. 1994. Skeletal effects of estrogen. Endocr. Rev. 15:275-300.

2. Smith, E., et al. 1994. Estrogen resistance caused by a mutation in the estrogen-receptor gene in a man. N. Engl. J. Med. 331:1056-1061.

3. Korach, K., et al. 1996. Estrogen receptor gene disruption: molecular characterization and experimental and clinical phenotypes. Recent Prog. Horm. Res. 51:159-186.

4. Horowitz, M. 1993. Cytokines and estrogen in bone: anti-osteoporotic effects. Science. 260:626-627.

5. Pensler, J.M., Radosevich, J.A., Higbee, R., and Langman, C.B. 1990. Osteoclasts isolated from membranous bone in children exhibit nuclear estrogen and progesterone receptors. J. Bone Miner. Res. 5:797-802.

6. Oursler, M., Osdoby, P., Pyfferoen, J., Riggs, B., and Spelsberg, T. 1991. Avian osteoclasts as estrogen target cells. Proc. Natl. Acad. Sci. USA. 88:6613-6617.

7. Oursler, M., Pederson, L., Fitzpatrick, L., Riggs, B., and Spelsberg, T. 1994. Human giant cell tumors of the bone (osteoclastomas) are estrogen target cells. Proc. Natl. Acad. Sci. USA. 91:5227-5231.

8. Mano, H., et al. 1996. Mammalian mature osteoclasts as estrogen target cells. Biochem. Biophys. Res. Commun. 223:637-642.

9. Hoyland, J., et al. 1997. Demonstration of estrogen receptor mRNA in bone using in situ reverse-transcriptase polymerase chain reaction. Bone. 20:87-92.

10. Kremer, M., Judd, J., Rifkin, B., Auszmann, J., and Oursler, M. 1995. Estrogen modulation of osteoclast lysosomal enzyme secretion. J. Cell. Biochem. 57:271-279.

11. Kameda, T., et al. 1997. Estrogen inhibits bone resorption by directly inducing apoptosis of the bone-resorbing osteoclasts. J. Exp. Med. 186:489-495.

12. Collier, F.M., et al. 1998. Osteoclasts from human giant cell tumors of bone lack estrogen receptors. Endocrinology. 139:1258-1267.

13. Riancho, J., and Mundy, G. 1995. The role of cytokines and growth factors as mediators of the effects of systemic hormones at the bone local level. Crit. Rev. Eukaryot. Gene Expr. 5:193-217.

14. Pacifici, R. 1996. Estrogen, cytokines, and pathogenesis of postmenopausal osteoporosis. J. Bone Miner. Res. 11:1043-1051.

15. Manolagas, S. 1995. Role of cytokines in bone resorption. Bone. 17:63S-67S.

16. Pacifici, R., et al. 1991. Effect of surgical menopause and estrogen replacement on cytokine release from human blood mononuclear cells. Proc. Natl. Acad. Sci. USA. 88:5134-5138.

17. Sato, F., et al. 1993. Effects of estrogen replacement on insulin-like growth factor I concentrations in serum and bone tissue and on interleukin 1 secretion from spleen macrophages in oophorectomized rats. Calcif. Tissue Int. 53:111-116

18. Bismar, H., Diel, I., Ziegler, R., and Pfeilschifter, J. 1995. Increased cytokine secretion by human bone marrow cells after menopause or discontinuation of estrogen replacement. J. Clin. Endocrinol. Metab. 80:3351-3355.

19. Reinhardt, R., Masada, M., Payne, J., Allison, A., and DuBois, L. 1994. Gingival fluid IL-1 beta and IL-6 levels in menopause. J. Clin. Periodontol. 21:22-25.

20. Girasole, G., et al. 1992. 17ß-estradiol inhibits interleukin- 6 production by bone marrow-derived stromal cells and osteoblasts in vitro: a potential mechanism for the antiosteoporotic effect of estrogens. J. Clin. Invest. 89:883-891.

21. Pacifici, R., et al. 1989. Ovarian steroid treatment blocks a postmenopausal increase in blood monocyte interleukin 1 release. Proc. Natl. Acad. Sci. USA. 86:2398-2402.

22. Kimble, R, et al. 1994. Interleukin-1 receptor antagonist decreases bone loss and bone resorption in ovariectomized rats. J. Clin. Invest. 93:1959-1967.

23. Kimble, R., Bain, S., and Pacifici, R. 1997. The functional block of TNF but not of IL-6 prevents bone loss in ovariectomized mice. J. Bone Miner. Res. 12:935-941.

24. Ammann, P., et al. 1997. Transgenic mice expressing soluble tumor necrosis factor-receptor are protected against bone loss caused by estrogen deficiency. J. Clin. Invest. 99:1699-1703.

25. Jilka, R., et al. 1992. Increased osteoclast development after estrogen loss: mediation by interleukin-6. Science. 257:88-91.

26. Ralston, S. 1994. Analysis of gene expression in human bone biopsies by polymerase chain reaction: evidence for enhanced cytokine expression in postmenopausal osteoporosis. J. Bone Miner. Res. 9:883-890.

27. Pacifici, R., et al. 1987. Spontaneous release of interleukin 1 from human blood monocytes reflects bone formation in idiopathic osteoporosis. Proc. Natl. Acad. Sci. USA. 84:4616-4620. 
28. Kawano, M., et al. 1989. Interleukin-1 beta rather than lymphotoxin as the major bone resorbing activity in human multiple myeloma. Blood. 73:1646-1649.

29. Tatakis, D. 1993. Interleukin-1 and bone metabolism: a review. J. Periodontol. 64:416-431.

30. Page, R. 1991. The role of inflammatory mediators in the pathogenesis of periodontal disease. J. Periodontal. Res. 26:230-242.

31. Hopkins, S., Humphreys, M., and Jayson, M. 1988. Cytokines in synovial fluid. I. The presence of biologically active and immunoreactive IL-1. Clin. Exp. Immunol. 72:422-427.

32. Hayashida, K., et al. 1992. Bone marrow changes in adjuvant-induced and collagen-induced arthritis. Arthritis Rheum. 35:241-245.

33. al Saffar, N., and Revell, P. 1994. Interleukin-1 production by activated macrophages surrounding loosened orthopaedic implants: a potential role in osteolysis. Br. J. Rheumatol. 33:309-316.

34. Gowen, M. 1992. Interleukin-1 and tumor necrosis factor. In Cytokines and bone metabolism. M. Gowen, editor. CRC Press. Ann Arbor, MI. 71-91.

35. Lorenzo, J. 1991. The role of cytokines in the regulation of local bone resorption. Crit. Rev. Immunol. 11:195-213.

36. Jimi, E., Shuto, T., and Koga, T. 1995. Macrophage colony-stimulating factor and interleukin-1 alpha maintain the survival of osteoclast-like cells. Endocrinology. 136:808-811.

37. Jimi, E., et al. 1998. Activation of NF-kappaB is involved in the survival of osteoclasts promoted by interleukin-1. J. Biol. Chem. 273:8799-8805.

38. Thomson, B., Saklatvala, J., and Chambers, T. 1986. Osteoblasts mediate interleukin 1 stimulation of bone resorption by rat osteoclasts. J. Exp. Med. 164:104-112

39. Yu, H., and Ferrier, J. 1993. Interleukin-1 alpha induces a sustained increase in cytosolic free calcium in cultured rabbit osteoclasts. Biochem. Biophys. Res. Commun. 191:343-350.

40. Jimi, E., et al. 1996. Interleukin-1 alpha activates an NF-kappaB-like factor in osteoclast-like cells. J. Biol. Chem. 271:4605-4608.

41. Xu, L., et al. 1996. Osteoclasts in normal and adjuvant arthritis bone tissues express the mRNA for both type I and II interleukin-1 receptors. Lab. Invest. 75:677-687.

42. Rothe, L., Collin-Osdoby, P., and Osdoby, P. 1995. Human osteoclast-like cell-derived IL-8 inhibits osteoblast alkaline phosphatase activity and is upregulated by IL-1.J. Bone Miner. Res. 10(Suppl. 1):T303. (Abstr.)

43. Rothe, L., et al. 1998. Human osteoclasts and osteoclast-like cells synthesize and release high basal and inflammatory stimulated levels of the potent chemokine IL-8. Endocrinology. 139:4353-4363.

44. Dinarello, C. 1996. Biological basis for interleukin-1 in disease. Blood. 87:2095-2147.

45. Anderson, F., et al. 1997. Isolation, culture and characterization of authentic human bone-resorptive osteoclasts. J. Bone Miner. Res. 12(Suppl. 1):T391. (Abstr.)

46. Collin-Osdoby, P., Oursler, M., Webber, D., and Osdoby, P. 1991. Osteoclastspecific monoclonal antibodies coupled to magnetic beads provide a rapid and efficient method of purifying avian osteoclasts. J. Bone Miner. Res. 6:1353-1365.

47. Osdoby, P., Anderson, F., Maloney, W., and Collin-Osdoby, P. 1999. Isolation and cultivation of osteoclasts and osteoclast-like cells. In Human cell culture. Kluwer Academic Publishers. Boston, MA. In press, vol. 4. M. Koller and B. Palsson, editors.

48. Galvin, R., Cullison, J., Avioli, L., and Osdoby, P. 1994. Influence of osteoclasts and osteoclast-like cells on osteoblast alkaline phosphatase activity and collagen synthesis. J. Bone Miner. Res. 9:1167-1178.

49. Cheng, S.-L., Yang, J., Rifas, L., Zhang, S.-F., and Avioli, L. 1994. Differentiation of human bone marrow osteogenic stromal cells in vitro: induction of the osteoblast phenotype by dexamethasone. Endocrinology. 134:277-286.

50. Rifas, L., Fausto, A., Scott, M.J., Avioli, L.V., and Welgus, H.G. 1994. Expression of metalloproteinases and tissue inhibitors of metalloproteinases in human osteoblast-like cells: differentiation is associated with repression of metalloproteinase biosynthesis. Endocrinology. 134:213-221.

51. Arts, J., et al. 1997. Differential expression of estrogen receptors alpha and beta mRNA during differentiation of human osteoblast SV-HFO cells.
Endocrinology. 138:5067-5070.

52. Rannevik, G., et al. 1995. A longitudinal study of the perimenopausal transition: altered profiles of steroid and pituitary hormones, SHBG and bone mineral density. Maturitas. 21:103-113.

53. Dana, S., Hoener, P., Wheeler, D., Lawrence, C., and McDonnell, D. 1994. Novel estrogen response elements identified by genetic selection in yeast are differentially responsive to estrogens and antiestrogens in mammalian cells. Mol. Endocrinol. 8:1193-1207.

54. Paech, K., et al. 1997. Differential ligand activation of estrogen receptors ER alpha and ER beta at AP1 sites. Science. 277:1508-1510.

55. Krishnan, V., Wang, X., and Safe, S. 1994. Estrogen receptor-Sp1 complexes mediate estrogen-induced cathepsin D gene expression in MCF-7 human breast cancer cells. J. Biol. Chem. 269:15912-15917.

56. Ye, K., Dinarello, C., and Clark, B. 1993. Identification of the promoter region of human interleukin 1 type I receptor gene: multiple initiation sites, high $\mathrm{G}+\mathrm{C}$ content, and constitutive expression. Proc. Natl. Acad. Sci. USA. 90:2295-2299.

57. Ye, K., Vannier, E., Clark, B.D., Sims, J.E., and Dinarello, C.A. 1996. Three distinct promoters direct transcription of different $5^{\prime}$ untranslated regions of the human interleukin 1 type I receptor: a possible mechanism for control of translation. Cytokine. 8:421-429.

58. Kurebayashi, S., et al. 1997. Characterization of mechanisms of interleukin-6 gene repression by estrogen receptor. J. Steroid Biochem. Mol. Biol. 60:11-17.

59. McKay, L., and Cidlowski, J. 1998. Cross-talk between nuclear factor-kappa $\mathrm{B}$ and the steroid hormone receptors: mechanisms of mutual antagonism. Mol. Endocrinol. 12:45-56.

60. Sims, J., Painter, S., and Gow, I. 1995. Genomic organization of the type I and type II IL-1 receptors. Cytokine. 7:483-490.

61. Colotta, F., et al. 1996. Regulated expression and release of the IL-1 decoy receptor in human mononuclear phagocytes. J. Immunol. 156:2534-2541.

62. Fuller, K., Owens, J.M., and Chambers, T.J. 1995. Macrophage inflammatory protein-1 alpha and IL-8 stimulate the motility but suppress the resorption of isolated rat osteoclasts. J. Immunol. 154:6065-6072.

63. Collin-Osdoby, P., et al. 1996. The chemokine IL-8 as an autocrine inhibitor of osteoclast bone resorptive activity via IL- 8 receptors expressed by avian osteoclasts and human osteoclast-like cells. J. Bone Miner. Res. 11(Suppl. 1):S357. (Abstr.)

64. Collin-Osdoby, P., Rothe, L., Bekker, S., and Anderson, F. 1998. Osteoclast recruitment, formation and bone resorptive activity are increased in paralel with neoangiogenesis on the chick chorioallantoic membrane in response to angiogenic peptides bFGF or IL-8. Bone. 23(Suppl.):SA094. (Abstr.)

65. Hughes, D., et al. 1996. Estrogen promotes apoptosis of murine osteoclasts mediated by TGF-beta. Nat. Med. 2:1132-1136

66. Oursler, M., et al. 1993. Estrogen modulation of avian osteoclast lysosomal gene expression. Endocrinology. 132:1373-1380.

67. Robinson, J., Riggs, B., Spelsberg, T., and Oursler, M. 1996. Osteoclasts and transforming growth factor-beta - estrogen-mediated isoform-specific regulation of production. Endocrinology. 137:615-621.

68. Fiorelli, G., et al. 1995. Functional estrogen receptors in a human preosteoclastic cell line. Proc. Natl. Acad. Sci. USA. 92:2672-2676.

69. Collin-Osdoby, P., et al. 1998. Calcitonin and estrogen receptor expression and inhibition of bone pit formation by isolated human osteoclasts. Bone. 23(Suppl.):SA096. (Abstr.)

70. Jakob, F., et al. 1997. Local estradiol metabolism in osteoblast- and osteoclast-like cells. J. Steroid Biochem. Mol. Biol. 61:167-174.

71. Vargas, S., et al. 1996. Interleukin-6 expression and histomorphometry of bones from mice deficient in receptors for interleukin-1 or tumor necrosis factor. J. Bone Miner. Res. 11:1736-1744.

72. Lorenzo, J., et al. 1998. Mice lacking the type I interleukin-1 receptor I do not lose bone mass after ovariectomy. Endocrinology. 139:3022-3025.

73. Pilbeam, C., et al. 1997. Downregulation of mRNA expression for the "decoy" interleukin-1 receptor-2 by ovariectomy in mice. J. Bone Miner. Res. 12(Suppl. 1):S433. (Abstr.)

74. Pacifici, R. 1998. Cytokines, estrogen, and postmenopausal osteoporosis: the second decade. Endocrinology. 139:2659-2661. 